\title{
Characterization of a new wheat- Aegilops biuncialis addition line conferring quality-associated HMW glutenin subunits
}

\author{
J.P. Zhou ${ }^{1}$, C.H. Yao ${ }^{1}$, E.N. Yang ${ }^{2}$, M.Q. Yin ${ }^{1}$, C. Liu ${ }^{1}$ and Z.L. Ren ${ }^{1,3}$ \\ ${ }^{1}$ School of Life Science and Technology, \\ University of Electronic Science and Technology of China, Chengdu, \\ Sichuan, People's Republic of China \\ ${ }^{2}$ Crop Research Institute, Sichuan Academy of Agricultural Sciences, \\ Chengdu, Sichuan, People's Republic of China \\ ${ }^{3}$ State Key Laboratory of Plant Breeding and Genetics, \\ Sichuan Agricultural University, Wenjiang, Chengdu, Sichuan, \\ People's Republic of China
}

Corresponding author: J.P. Zhou

E-mail: zhoujp@uestc.edu.cn

Genet. Mol. Res. 13 (1): 660-669 (2014)

Received January 11, 2013

Accepted May 17, 2013

Published January 28, 2014

DOI http://dx.doi.org/10.4238/2014.January.28.11

\begin{abstract}
In this study, a new disomic addition line, 12-5-2, with 44 chromosomes that was derived from $\mathrm{BC}_{3} \mathrm{~F}_{2}$ descendants of the hybridization between Triticum aestivum cv. CN19 and Aegilops biuncialis was created and reported. 12-5-2 was immune to both powdery mildew and stripe rust and has stable fertility. Fluorescence in situ hybridization and C-banding revealed that $12-5-2$ was a $1 \mathrm{U}^{\mathrm{b}}$ disomic addition line $\left(\mathrm{ADL} 1 \mathrm{U}^{\mathrm{b}}\right)$. The seed storage protein electrophoresis showed that 12-5-2 presented all high molecular weight glutenin subunits $(7+8$ and $2+12)$ of $\mathrm{CN} 19$ and 2 new subunits that were designated $\mathrm{Ux}$ and $\mathrm{Uy}$. Additionally, the flour quality parameters
\end{abstract}


showed that the protein content, Zeleny sedimentation value, wet gluten content, and grain hardness of 12-5-2 were significantly higher than those of its parent CN19. Moreover, 5 pairs of the chromosome $1 \mathrm{U}^{\mathrm{b}}$-specific polymerase chain reaction-based landmark unique gene markers, TNAC1021, TNAC1041, TNAC1071, TNAC1-01, and TNAC1-04, were also obtained. The new ADL1U ${ }^{\mathrm{b}} 12-5-2$ could be a valuable source for wheat improvement, especially for wheat endproduct quality and resistance to disease.

Key words: Aegilops biuncialis; Bread-making quality; C-banding; High molecular weight glutenin

\section{INTRODUCTION}

Aegilops species play an important role in the evolution of cultivated wheat and the processes of improving the genetic variation of common wheat (Triticum aestivum L.) (McFadden and Sears, 1946). Aegilops species carry many agronomically important features such as disease resistance, insect and pest resistance (Gill et al., 1985, 1987; Raupp et al., 1993, 1995; Gradzielewska et al., 2012), drought tolerance (Molnár et al., 2004), salt tolerance (Colmer et al., 2006), and high protein quality (Garg et al., 2009a,b). It was therefore used widely as a valuable source for wheat improvement. Until now, more than 200 wheat-Aegilops interspecific hybrid, addition, and translocation lines have been developed, and 53 disease and insect resistance genes have been incorporated into the wheat gene pool from 15 Aegilops species (for review see Schneider et al., 2008a).

Aegilops biuncialis $\left(2 \mathrm{n}=4 \mathrm{x}=28, \mathrm{U}^{\mathrm{b}} \mathrm{U}^{\mathrm{b}} \mathrm{M}^{\mathrm{b}} \mathrm{M}^{\mathrm{b}}\right)$ is a wild species that is closely related to cultivated wheat and has a great number of agronomically useful traits including drought and salt tolerance, disease resistance, and special high molecular weight glutenin subunits (HMW-GSs) (Damania and Pecetti, 1990; Makkouk et al., 1994; Molnár et al., 2004; Colmer et al., 2006; Tan et al., 2009). These useful genes can be incorporated into cultivated wheat by developing addition lines, substitution lines, or translocation lines (Schneider et al., 2005, 2008b; Molnár et al., 2009; Schneider and Molnár-Láng, 2012).

The HMW-GSs that are encoded by many allelic genes are one class of wheat prolamins. Two linked genes designated as $\mathrm{x}$ - and y-types are located on the long arms of homeologous group 1 chromosomes. The HMW-GSs have been found to have a major effect on bread-making quality (Payne et al., 1981). Because of the importance of HMW-GSs in wheat quality improvement, a large number of wheat HMW-GS alleles have been cloned (Forde et al., 1985; Thompson et al., 1985; Anderson and Greene, 1989; Wan et al., 2002; Feng et al., 2011). In spite of numerous investigations aimed at finding functionally useful HMW-GSs in wheat, only a very limited number have shown functional differences. Screening for "good quality subunits" in related wild wheat species is therefore important for improving breadmaking quality. Only the potential good-quality subunits, Glu-1E from the chromosome $1 \mathrm{E}$ addition line of Agropyron elongatum (DAL1E) and the Glu-1S subunit from the chromosome 1S addition line of Aegilops searsii (DAL1Ss) were identified so far (Garg et al., 2009a,b).

This study was undertaken to identify a new wheat-A. biuncialis addition line, evaluate its HMW-GSs from A. biuncialis for improving wheat bread-making quality, and select the 
polymerase chain reaction (PCR)-based landmark unique gene (PLUG) markers specific to the homeologous group 1 chromosomes of $A$. biuncialis.

\section{MATERIAL AND METHODS}

\section{Materials}

The wheat- $A$. biuncialis addition line 12-5-2 was created and released by our research group, which was derived from the hybridization between T. aestivum cv. Chuannong 19 (CN19), an elite cultivar and A. biuncialis. The creation procedure was as follows: $\mathrm{F}_{1}$ hybrid plants were produced by $\mathrm{CN} 19 \times$ A. biuncialis, and then these $\mathrm{F}_{1}$ hybrids (ABDU ${ }^{\mathrm{b}} \mathrm{M}^{\mathrm{b}}, 2 \mathrm{n}$ $=5 \mathrm{x}=35$ ) were treated with colchicine at the tillering stage to produce amphiploid plants $\left(\right.$ AABBDDU $\left.{ }^{b} U^{b} M^{b} M^{b}, 2 n=10 x=70\right)$, which were backcrossed with wheat and then selfed. Line 12-5-2 was one of the $\mathrm{BC}_{3} \mathrm{~F}_{2}$ descendants. Chinese Spring (CS), CN19, and A. biuncialis were collected and preserved by our lab.

\section{Somatic chromosome counts and meiosis analysis}

To count somatic chromosomes, seedling root tips were kept in water at $0^{\circ} \mathrm{C}$ for 24 $\mathrm{h}$ and were fixed in ethanol-acetic acid (3:1) for at least 3 days. They were then stained using the conventional Feulgen method. Anthers with pollen mother cells (PMCs) at metaphase I (MI) were fixed in Carnoy's 6:3:1 (ethanol:acetic acid:chloroform) fixative, and meiosis was studied using the conventional acetocarmine procedure.

\section{Giemsa C-banding}

The C-banding was carried out according to the protocol that was described by Gill et al. $(1991 \mathrm{a}, \mathrm{b})$ with the following changes: root tips were pretreated in water at $0^{\circ} \mathrm{C}$ for $22 \mathrm{~h}$ and fixed for 3 days or longer (up to 1 week) at room temperature, and preparations were incubated for $2 \mathrm{~min}$ in $0.2 \mathrm{~N} \mathrm{HCl}$ in a water bath at $60^{\circ} \mathrm{C}$ and treated in a $5 \%$ barium hydroxide solution at room temperature for $7.5 \mathrm{~min}$. Photographs were taken with a cooled CCD camera system (DP70) on an Olympus BX-51 fluorescence microscope.

\section{Fluorescence in situ hybridization (FISH)}

The clone pTa71, containing a 9.05-kb EcoRI fragment of rDNA isolated from wheat (Gerlach and Bedbrook, 1979) was generously provided by Dr. B. Friebe of Wheat Germplasm Resource Center, Department of Plant Pathology, Kansas State University, USA. The plasmid was also labeled with digoxigenin-11-dUTP by nick translation based on the protocols of the manufacturer (Roche Diagnostics Indianapolis, IN, USA). Hybridization was carried out according to Jiang et al. (1996). The detection of digoxigenin was carried out with fluorescein-conjugated anti-digoxigenin Fab fragment (Roche Diagnostics). The slides were finally mounted in vectashield antifade solution (Vector Laboratories, Burlingame, CA, USA) containing $0.25 \mu \mathrm{g} / \mathrm{mL}$ propidium iodide. Slides were examined on an Olympus BX-51 fluorescence microscope. Photographs were taken with a cooled CCD camera system 
(DP70 on an Olympus BX-51 fluorescence microscope).

\section{Seed storage protein electrophoresis and quality testing}

Sodium dodecyl sulfate-polyacrylamide gel electrophoresis (SDS-PAGE) was used to separate endosperm glutenin proteins according to the procedure of Yang et al. (2001). Quality testing was carried out according to Zhang et al. (2005).

\section{PLUG marker analysis}

Total genomic DNA from wheat materials CS, CN19, A. biuncialis, and 12-5-2 were extracted as described previously (Zhou et al., 2012). A total of 48 pairs of PLUG markers, including 22 that were group 1 primers in Ishikawa et al. (2009) and 26 (TNAC1-01, TNAC1$02, \ldots$, TNAC1-26) that were designed by us, were used in this study. PCR was performed in $25-\mu \mathrm{L}$ reaction volumes containing the following reagents: $50 \mathrm{ng}$ template DNA, $0.2 \mathrm{mM}$ of each dNTP, $4 \mu \mathrm{M}$ of each primer, $1.5 \mathrm{mM} \mathrm{MgCl}_{2}$, Taq DNA polymerase buffer, and $1.0 \mathrm{U}$ Taq DNA polymerase (Takara, Japan). The PCR program consisted of a 3-min initial denaturation step at $94^{\circ} \mathrm{C} ; 35$ cycles with denaturation at $94^{\circ} \mathrm{C}$ for $45 \mathrm{~s}$, annealing at $57^{\circ}-60^{\circ} \mathrm{C}$ for $45 \mathrm{~s}$, and extension at $72^{\circ} \mathrm{C}$ for $2 \mathrm{~min}$; and a final extension step at $72^{\circ} \mathrm{C}$ for $5 \mathrm{~min}$. To obtain higher levels of polymorphism, PCR products were digested with the 4-base cutter restriction endonucleases TaqI and/or HaeIII. The products were separated by electrophoresis with 1.2\% agarose gels.

\section{RESULTS}

\section{Agronomic traits and cytological observation of the 12-5-2 addition line}

Line 12-5-2 was obtained from $\mathrm{BC}_{3} \mathrm{~F}_{2}$ descendants of the hybridization between $\mathrm{CN} 19$ and $A$. biuncialis. Its agronomic traits were very close to those of its wheat parent $\mathrm{CN} 19$. Its adult plant height was around $85 \mathrm{~cm}$, and the number of spikes per plant varied from 4 to 7. Additionally, line 12-5-2 has stable fertility and immunity to wheat powdery mildew and stripe rust under both inoculated and natural conditions in all growth stages. However, the kernels of 12-5-2 changed to be black at harvest stage (Figure 1).

Moreover, the somatic chromosome number per cell of 12-5-2 was 44. It was observed to produce 22 bivalents and had a very low probability of univalents and multivalents in meiotic MI of PMCs. These above results demonstrated that the 12-5-2 line was a disomic addition line and it would act as a resource for a continuous supply of desirable genes from $A$. biuncialis to wheat.

\section{FISH and C-banding of the 12-5-2 addition line}

The DNA probe pTa71 was used to detect the presence of satellite chromosomes in line 12-5-2. As illustrated in Figure 2A, 4 chromosome pairs were detected. Compared with the hybridization patterns of pTa71 in wheat (Appels et al., 1980), we know that 1 satellite chromosome pair from A. biuncialis was incorporated into line 12-5-2 besides chromosomes $1 \mathrm{~B}, 6 \mathrm{~B}$, and $5 \mathrm{D}$. 

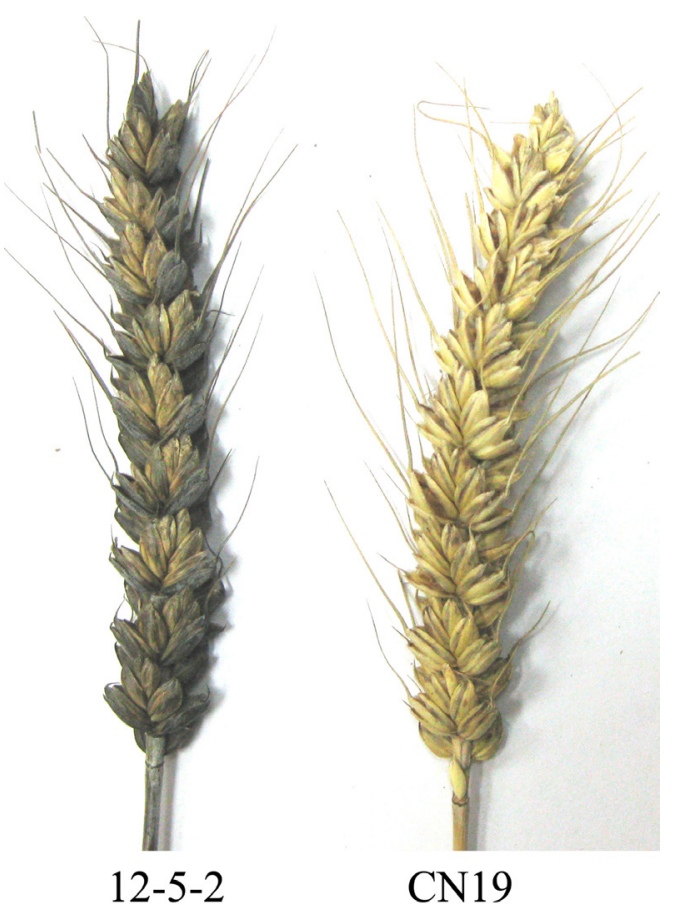

Figure 1. Kernels of 12-5-2 and CN19.
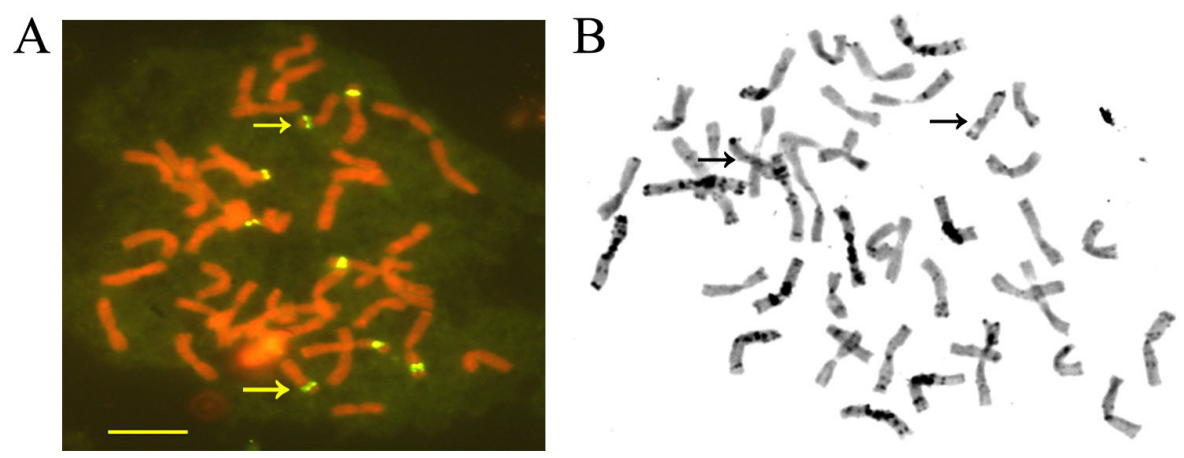

Figure 2. A. FISH on the mitotic chromosomes of 12-5-2 using pTa71 as probe. B. Giemsa C-banding of 12-5-2. The chromosome pair $1 \mathrm{U}^{\mathrm{b}}$ was indicated by arrows. Bar $=10 \mu \mathrm{m}$.

In addition, Giemsa $\mathrm{C}$-banding was also used to further identify the satellite chromosomes from A. biuncialis in line 12-5-2. Two satellite chromosomes presented a prominently terminal dark band on the long arm (Figure 2B). We also observed that the extra satellite chromosome in 12-5-2 was $1 \mathrm{U}^{\mathrm{b}}$ according to the standard karyotype of wheat (Gill et al., 1991b) and A. biuncialis (Badaeva et al., 2004). Based on the above data, it can be concluded safely that $12-5-2$ was a $1 \mathrm{U}^{\mathrm{b}}$ disomic addition line. 


\section{HMW-glutenin and quality testing of 12-5-2}

The seed glutenin composition of CS, A. biuncialis, 12-5-2, and CN19 was analyzed by SDS-PAGE. As illustrated in Figure 3, both CN19 and CS contained the HMW-GSs of $7+$ 8, and $2+12$, encoded by Glu-B1 and Glu-D1, respectively. Line 12-5-2 exhibited all HMWGSs $(7+8$ and $2+12)$ of CN19 and 2 new subunits that were designated Ux and Uy, which apparently originated from parent $A$. biuncialis. This result strongly supported the idea that 12-5-2 was a $1 \mathrm{U}^{\mathrm{b}}$ disomic addition line.

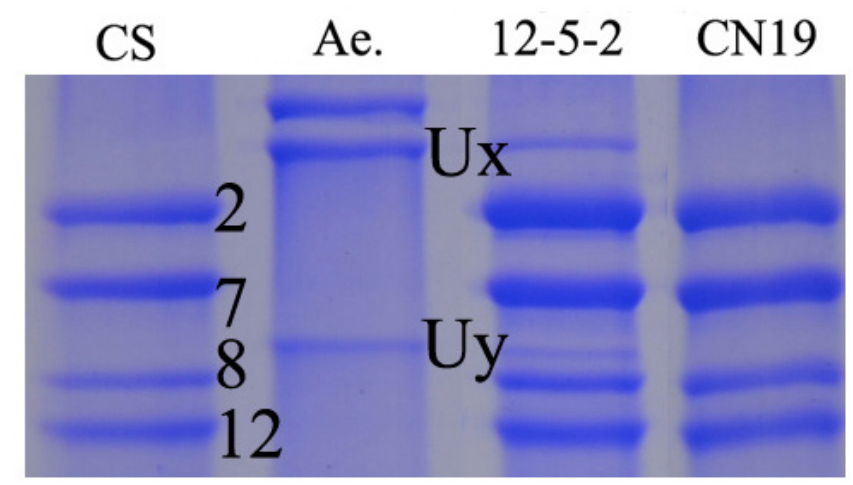

Figure 3. Seed storage protein profiles of 12-5-2. CS = Chinese Spring; Ae. = Aegilops biuncialis .

Moreover, the flour quality parameters of protein content, Zeleny sedimentation value, wet gluten content, grain hardness, mixing time, mixing tolerance, water content, and water absorption were tested. The quality data (Table 1 ) showed that the protein content, Zeleny sedimentation value, wet gluten content, and grain hardness of 12-5-2 were significantly higher than those of its parent $\mathrm{CN} 19$. These results indicated that $1 \mathrm{U}^{\mathrm{b}}$ has a potential to improve wheat end-product quality.

Table 1. Grain and flour characteristics of 12-5-2.
\begin{tabular}{lcccccccc}
\hline Species & $\begin{array}{c}\text { Content of } \\
\text { protein }(\%)\end{array}$ & $\begin{array}{c}\text { Zeleny sedimentation } \\
\text { value }\left(\mathrm{cm}^{3}\right)\end{array}$ & $\begin{array}{c}\text { Wet gluten } \\
\text { content }(\%)\end{array}$ & $\begin{array}{c}\text { Grain } \\
\text { hardness }\end{array}$ & $\begin{array}{c}\text { Mixing time } \\
(\mathrm{min})\end{array}$ & $\begin{array}{c}\text { Mixing tolerance } \\
(\mathrm{min})\end{array}$ & $\begin{array}{c}\text { Content of } \\
\text { water }(\%)\end{array}$ & $\begin{array}{c}\text { Water absorption } \\
(\%)\end{array}$ \\
\hline CN19 & 15.1 & 51.3 & 33.1 & 67.9 & 1.7 & 2.5 & 10.5 & 52.1 \\
$12-5-2$ & 20.0 & 60.9 & 40.9 & 75.5 & 2.0 & 2.6 & 10.0 & 52.4 \\
\hline
\end{tabular}

\section{The chromosome $1 U^{\mathrm{b}}$-specific PLUG markers}

Five pairs of the chromosome $1 \mathrm{U}^{\mathrm{b}}$-specific PLUG markers, TNAC1021, TNAC1041, TNAC1071, TNAC1-01, and TNAC1-04, were obtained from 48 pairs of the screening markers (Table 2; Figure 4). As shown in Figure 4, except for $21 \mathrm{U}^{\mathrm{b}}$-specific bands that were identified in TNAC1071 + HaeIII (Figure 4A), only one $1 \mathrm{U}^{\mathrm{b}}$-specific band was observed from each primer + TaqI or HaeIII (Figure 4B-F). These results can be used in further research. 


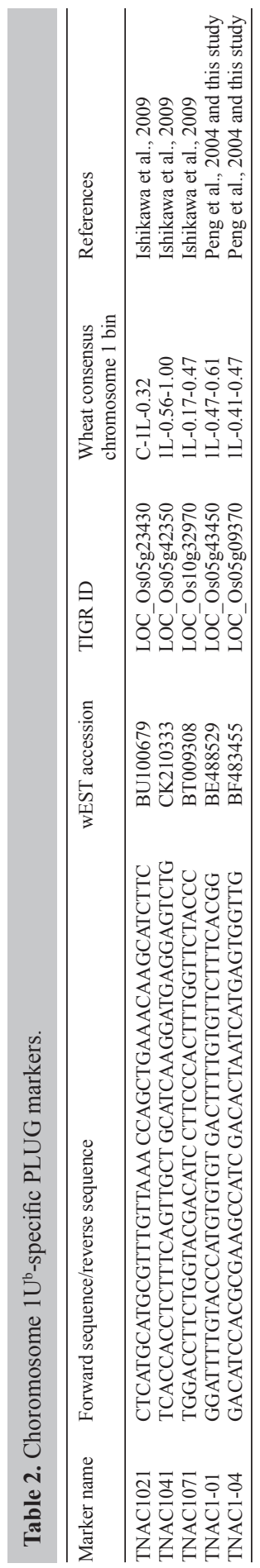




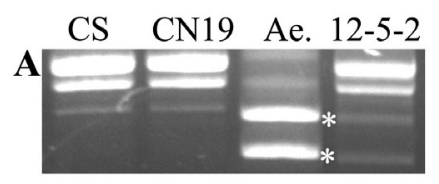

TNAC1071+HaeIII

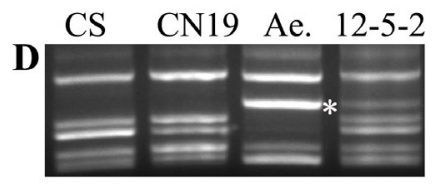

TNAC1-01+Taq I

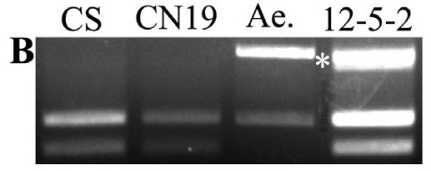

TNAC1-04+HaeIII

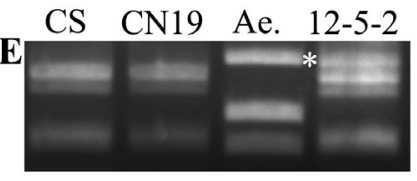

TNAC1041+TaqI
CS CN19 Ae. 12-5-2

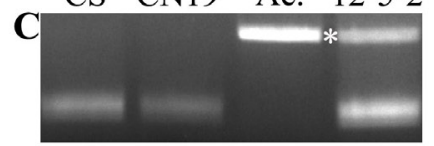

TNAC1-04+TaqI

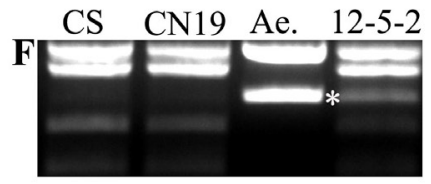

TNAC1021+TaqI

Figure 4. Agarose gel electrophoresis pattern of the PLUG-PCR markers. The chromosome-specific bands were indicated by asterisk. $\mathrm{CS}=$ Chinese Spring; Ae. = Aegilops biuncialis.

\section{DISCUSSION}

The development of wheat- A. biuncialis chromosome addition lines allows the study of the genetic effects of individual alien chromosomes in cultivated wheat. In previous studies, 7 wheat- A. biuncialis disomic addition lines $\left(2 \mathrm{U}^{\mathrm{b}}, 2 \mathrm{M}^{\mathrm{b}}, 3 \mathrm{U}^{\mathrm{b}}, 3 \mathrm{M}^{\mathrm{b}}, 5 \mathrm{U}^{\mathrm{b}}, 6 \mathrm{M}^{\mathrm{b}}\right.$, and $\left.7 \mathrm{U}^{\mathrm{b}}\right)$ were created, and all of these addition lines had reduced fertility compared with that of the parent (Schneider et al., 2005; Schneider and Molnár-Láng, 2012). In this study, a new wheat- $A$. biuncialis disomic addition line $1 \mathrm{U}^{\mathrm{b}}$ was created and identified, and the agronomic traits were very close to those of the wheat parent $\mathrm{CN} 19$. The addition line $1 \mathrm{U}^{\mathrm{b}}$ also has stable fertility and heredity compared with that of the parent, suggesting that the wheat CN19 has compatibility with the donor chromosome $1 \mathrm{U}^{\mathrm{b}}$. Therefore, the addition line $1 \mathrm{U}^{\mathrm{b}}$ can be used in wheat breeding directly or as a secondary gene resource.

Very few chromosome-specific molecular markers have been described in Aegilops species (Gill et al., 1991a; Zhang et al., 2001; Adonina et al., 2005). As for A. biuncialis, only 2 simple sequence repeat (SSR) markers (GWM44 and GDM61) were obtained from 108 wheat SSR markers, which gave specific PCR products from the $2 \mathrm{M}^{\mathrm{b}}$ and $3 \mathrm{M}^{\mathrm{b}}$ wheat- $A$. biuncialis addition lines (Schneider et al., 2010; Schneider and Molnár-Láng, 2012). In this study, 5 pairs of PLUG markers that were specific to the $1 \mathrm{U}^{\mathrm{b}}$ chromosome were obtained from 48 pairs (Table 2; Figure 4). Therefore, it is not difficult to screen and obtain other $\mathrm{U}^{\mathrm{b}}$ - and $\mathrm{M}^{\mathrm{b}}$-specific PLUG markers.

Two factors, protein content and protein quality, play a key role in flour bread-making quality. Previous studies indicated that increases in protein content do not always accompany increases in dough strength except for DAL1Ss from A. searsii and DAL1E from Agropyron longatum. For example, although the DAL1U from A. umbellulata contained a large size of x-type HMW-GSs and the protein content was significantly higher than its parent CS, the dough strength was insignificantly different from that of CS (Garg et al., 2009a,b), suggesting that factors such as $\beta$-spiral structures of repeat units, conservation of repeats, and interactions between different glutenins and gliadins from different sources may be more important contributors to dough strength. In this study, the protein content, Zeleny sedimentation value, wet gluten content, and grain hardness of 12-5-2 were significantly higher than those of its parent CN19. This indicates a positive effect of gluten proteins from A. biuncialis on dough strength. 


\section{ACKNOWLEDGMENTS}

Research supported by the Fundamental Research Funds for the Central Universities (\#ZYGX2010J103 and \#ZYGX2011J095) and the National Natural Science Foundation of China (\#30800685).

\section{REFERENCES}

Adonina IG, Salina EA, Pestsova EG and Roder MS (2005). Transferability of wheat microsatellites to diploid Aegilops species and determination of chromosomal localizations of microsatellites in the $\mathrm{S}$ genome. Genome 48: 959-970.

Anderson OD and Greene FC (1989). The characterization and comparative analysis of high-molecular-weight glutenin genes from genomes A and B of a hexaploid bread wheat. Theor. Appl. Genet. 77: 689-700.

Appels R, Gerlach WL, Dennis ES, Swift H, et al. (1980). Molecular and chromosomal organization of DNA sequences coding for the ribosomal RNAs in cereals. Chromosoma 78: 293-311.

Badaeva ED, Amosova AV, Samatadze TE, Zoshchuk SA, et al. (2004). Genome differentiation in Aegilops. 4. Evolution of the U-genome cluster. Plant Systemat. Evol. 246: 45-76.

Colmer TD, Flowers TJ and Munns R (2006). Use of wild relatives to improve salt tolerance in wheat. J. Exp. Bot. 57: 1059-1078.

Damania AB and Pecetti L (1990). Variability in a collection of Aegilops species and evaluation for yellow rust resistance at two locations in Northern Syria. J. Genet. Breed. 44: 97-102.

Feng B, An XL, Xu ZB, Liu DC, et al. (2011). Molecular cloning of a novel chimeric HMW glutenin subunit gene 1Dx5' from a common wheat line W958. Mol. Breed. 28: 163-170.

Forde J, Malpica JM, Halford NG, Shewry PR, et al. (1985). The nucleotide sequence of a HMW glutenin subunit gene located on chromosome 1A of wheat (Triticum aestivum L.). Nucleic Acids Res. 13: 6817-6832.

Garg M, Tanaka H, Ishikawa N, Takata K, et al. (2009a). A novel pair of HMW glutenin subunits from Aegilops searsii improves quality of hexaploid wheat. Cereal Chem. 86: 26-32.

Garg M, Tanaka H, Ishikawa N, Takata K, et al. (2009b). Agropyron elongatum HMW-glutenins have a potential to improve wheat end-product quality through targeted chromosome introgression. J. Cereal Sci. 50: 358-363.

Gerlach WL and Bedbrook JR (1979). Cloning and characterization of ribosomal RNA genes from wheat and barley. Nucleic Acids Res. 7: 1869-1885.

Gill BS, Sharma HC, Raupp WJ, Browder LE, et al. (1985). Evaluation of Aegilops species for resistance to wheat powdery mildew, wheat leaf rust, Hessian fly and greenbug. Plant Breed. 69: 314-316.

Gill BS, Hatchett JH and Raupp WJ (1987). Chromosomal mapping of Hessian fly resistance gene H13 in the D genome of wheat. J. Hered. 78: 97-100.

Gill KS, Lubbers EL, Gill BS, Raupp WJ, et al. (1991a). A genetic linkage map of Triticum tauschii (DD) and its relationship to the D genome of bread wheat (AABBDD). Genome 34: 362-374.

Gill BS, Friebe B and Endo TR (1991b). Standard karyotype and nomenclature system for description of chromosome bands and structural aberrations in wheat (Triticum aestivum). Genome 34: 830-839.

Gradzielewska A, Gruszecka D, Lesniowska-Nowak J and Paczos-Grzeda E (2012). Identification of hybrids between triticale and Aegilops juvenalis (Thell.) Eig and determination of genetic similarity with ISSRs. Genet. Mol. Res. 11: 2147-2155.

Ishikawa G, Nakamura T, Ashida T, Saito M, et al. (2009). Localization of anchor loci representing five hundred annotated rice genes to wheat chromosomes using PLUG markers. Theor. Appl. Genet. 118: 499-514.

Jiang J, Hulbert SH, Gill BS and Ward DC (1996). Interphase fluorescence in situ hybridization mapping: a physical mapping strategy for plant species with large complex genomes. Mol. Gen. Genet. 252: 497-502.

Makkouk KM, Comeau A and Ghulam W (1994). Resistance to barley yellow dwarf luteovirus in Aegilops species. Can. J. Plant Sci. 74: 631-634.

McFadden ES and Sears ER (1946). The origin of Triticum spelta and its free-threshing hexaploid relatives. J. Hered. 37 : 81-107.

Molnár I, Gáspár L, Sárvári É, Dulai S, et al. (2004). Physiological and morphological responses to water stress in Aegilops biuncialis and Triticum aestivum genotypes with differing tolerance to drought. Funct. Plant Biol. 31: 1149-1159.

Molnár I, Benavente E and Molnar-Lang M (2009). Detection of intergenomic chromosome rearrangements in irradiated Triticum aestivum - Aegilops biuncialis amphiploids by multicolour genomic in situ hybridization. Genome 52: 156-165. 
Payne PI, Corfied KG, Hoft LM and Blackman JA (1981). Correlations between the inheritance of certain high-molecular weight subunits of glutenin and bread-making quality in progenies of six crosses of bread wheat. J. Sci. Food Agr. 32: 51-60.

Peng JH, Zadeh H, Lazo GR, Gustafson JP, et al. (2004). Chromosome bin map of expressed sequence tags in homoeologous group 1 of hexaploid wheat and homoeology with rice and Arabidopsis. Genetics 168: 609-623.

Raupp WJ, Amri A, Hatchett JH, Gill BS, et al. (1993). Chromosomal location of Hessian fly-resistance genes H22, H23 and $\mathrm{H} 24$ derived from Triticum tauschii in the D genome of wheat. J. Hered. 84: 142-145.

Raupp WJ, Gill BS, Friebe B, Wilson DL, et al (1995). The Wheat Genetics Resource Center: Germ Plasm Conservation, Evaluation and Utilization. In: Proceedings of the 8th International Wheat Genetic Symposium (Li ZS and Xin ZY, eds.). China Agricultural Scientech Press, Beijing, 469-475.

Schneider A and Molnár-Láng M (2012). Detection of various U and M chromosomes in wheat - Aegilops biuncialis hybrids and derivatives using fluorescence in situ hybridisation and molecular markers. Czech J. Genet. Plant Breed. 48: 169-177.

Schneider A, Linc G, Molnar I and Molnar-Lang M (2005). Molecular cytogenetic characterization of Aegilops biuncialis and its use for the identification of 5 derived wheat - Aegilops biuncialis disomic addition lines. Genome 48: 10701082.

Schneider A, Molnár I and Molnár-Láng M (2008a). Utilisation of Aegilops (goatgrass) species to widen the genetic diversity of cultivated wheat. Euphytica 163: 1-19.

Schneider A, Molnár I and Molnár-Láng M (2008b). Incorporation of Aegilops biuncialis chromosomes into wheat and their identification using fluorescent in situ hybridization. Acta Biol. Szegediensis 52: 133-137.

Schneider A, Molnár I and Molnár-Láng M (2010). Selection of U and M genome-specific wheat SSR markers using wheat - Aegilops biuncialis and wheat - Ae. geniculata addition lines. Euphytica 175: 357-364.

Tan FQ, Zhou JP, Yang ZJ, Zhang Y, et al. (2009). Characterization of a new synthetic wheat - Aegilops biuncialis partial amphiploid. Afr. J. Biotechnol. 8: 3215-3218.

Thompson RD, Bartels D and Harberd NP (1985). Nucleotide sequence of a gene from chromosome 1D of wheat encoding a HMW-glutenin subunit. Nucleic Acids Res. 13: 6833-6846.

Wan Y, Wang D, Shewry R and Halford G (2002). Isolation and characterization of five novel high molecular weight subunit of glutenin genes from Triticum timopheevi and Aegilops cylindrica. Theor. Appl. Genet. 104: 828-839.

Yang ZJ, Li GR, Jiang HR and Ren ZL (2001). Expression of nucleolus, endosperm storage proteins and disease resistance in an amphiploid between Aegilops tauschii and Secale silvestre. Euphytica 119: 317-321.

Zhang H, Reader SM, Liu X, Jia JZ, et al. (2001). Comparative genetic analysis of the Aegilops longissima and Ae. sharonensis genomes with common wheat. Theor. Appl. Genet. 103: 518-525.

Zhang Y, Zhang Y, He ZH and Ye GY (2005). Milling quality and protein properties of autumn-sown Chinese wheats evaluated through multi-location trials. Euphytica 143: 209-222.

Zhou JP, Zhang HY, Yang ZJ, Li GR, et al. (2012). Characterization of a new T2DS.2DL-?R translocation triticale ZH-1 with multiple resistances to diseases. Genet. Resour. Crop Evol. 59: 1161-1168. 